\section{Sigmoid Diverticular Perforation Relating to the Migration of a Polyethylene Endoprosthesis}

We report here the case of an 86-year-old woman with jaundice related to cancer of the pancreas. During endoscopic retrograde cholangiography, failure to place a plastic endoprosthesis occurred: the endoprosthesis was unfortunately dropped and lost in the duodenal lumen. Biliary stenting was achieved by two selfexpanding metal stents (Acuflex stents) via a percutaneous transhepatic route.

Four days later, the patient complained of transient abdominal pain. Abdominal radiography and CT scanning showed that positions of the metal stents and plastic endoprosthesis had not changed (Figure 1), and the patient was discharged. Three weeks later, severe abdominal pain occurred. Abdominal radiography showed a pneumoperitoneum and the migration of the plastic endoprosthesis down to a pelvic location (Figure 2). Surgery disclosed a sigmoid diverticular perforation related to the impaction of the plastic endoprosthesis, requiring a sigmoidectomy. The patient was discharged ten days later, and died two months afterwards.

The risk of migration of a plastic endoprosthesis should not be underestimated. Mueller et al. found a $6 \%$ migration rate (1), but the true incidence is not certain (2). In addition, the management of a migrated endoprosthesis is not well defined. To the best of our knowledge, this is the first case of colonic perforation relating to a migrated plastic endoprosthesis. Ruffolo et al. reported a similar observation without perforation (3). In such cases, they proposed three to four weeks of observation with serial abdominal radiography to ensure that the plastic endoprosthesis had been expelled. We would agree with this position, which would probably have helped us to prevent the colonic perforation in our patient. Although the patient spent a significant part of the remaining period of her life in hospital, the potential benefit of placing a plastic endoprosthesis is not in doubt, In terms of quality of life and cost, a medical history of colonic diverticula indicates a need for management with plastic endoprostheses $(3,4)$.

V. Baty, B. Denis, M. A. Bigard, P. Gaucher

Hepatology and Gastroenterology Service, Centre Hospitalier

Universitaire de Nancy, Hôpitaux de Brabois, Vandoeuvre, France

\section{References}

1. Mueller PR, Ferrucci JT, Teplick SK, et al. Biliary stent endoprosthesis: analysis of complications in 113 patients. Radiology 1985; 156: 637-9.

2. Johanson JF, Schmalz MJ, Geenen JE. Incidence and risk factors for biliary and pancreatic stent migration. Gastrointest Endose 1992: 38: $341-6$.

3. Ruffolo TA, Lehman GA, Sherman S et al. Biliary stent migration with colonic diverticular impaction. Gastrointest Endose 1992; 38: $81-3$.

4. Cotton PB, Schmitt C. Quality of life in palliative management of malignant obstructive jaundice. Scand J Gastroenterol 1993 ; 28 (Suppl 199): 44-6.

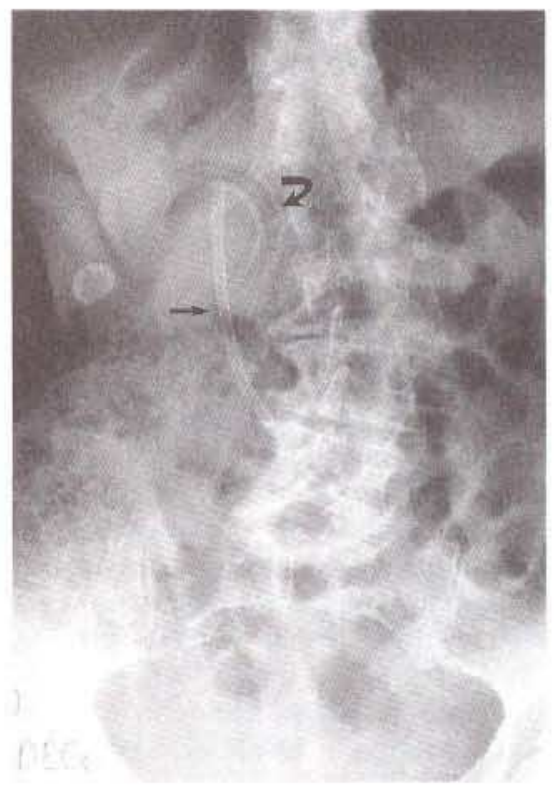

Figure 1: The plastic endoprosthesis (straight arrow) and metal stents (curved arrow) remained in the same position three days after stenting

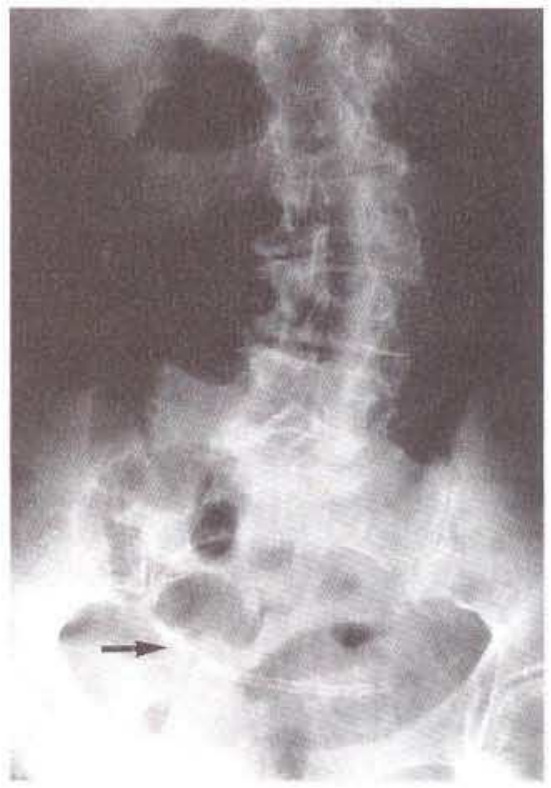

Figure 2: The plastic endoprosthesis had migrated to a pelvic position (arrow) three weeks after biliary stenting.
Corresponding Author

V. Baty, M.D.

Service d'Hépatologie et de Gastroentérologie CHU de Nancy, Hôpitaux de Brabois

Rue du Morvan 54511 Vandoeuvre-les-Nancy

France

Fax:+33-83153661 